\title{
Prevalence of new and known species of haemoparasites in feral pigeons in northwest Italy
}

\author{
Frine Eleonora Scaglione ${ }^{1 *}$, Paola Pregel ${ }^{1}$, Francesca Tiziana Cannizzo ${ }^{1}$, Antón David Pérez-Rodríguez², \\ Ezio Ferroglio ${ }^{1}$ and Enrico Bollo ${ }^{1}$
}

\begin{abstract}
Background: Haemoparasites in feral pigeons have been studied in several countries but no data are available from Italy. The aim of this work was to evaluate the prevalence and diversity of Haemoproteus spp./Plasmodium spp. and Leucocytozoon spp. in feral pigeons from northwest Italy, as well as the association between infection and host age or sex.

Methods: Feral pigeons were collected during a regional culling programme from the Piedmont region (northwest Italy) and subjected to necropsy. Infections were detected from DNA extracted from the spleen following a nested PCR protocol. The association between sex or age and infection status was evaluated using the chi-squared test for independence or Fisher's exact test.

Results: Out of 51 animals, 15 were positive for Haemoproteus/Plasmodium spp. and eight for Leucocytozoon spp., with a significant difference between haemoparasites prevalence. There was no significant association between age or sex and infection status. The coinfection with different haemoparasites was very significant $(p<0.01)$, showing a greater relative risk to be infected by a second haemoparasite in birds already infected, in particular in male and in adult pigeons. DNA sequencing of Leucocytozoon spp. showed six different lineages in pigeons, and one of Haemoproteus and Plasmodium, respectively.

Conclusions: Blood parasites are continuously circulating around the world, and the results presented in the paper suggest that cross infection of feral pigeons with haemoparasites typical of other migratory or nonmigratory bird species is possible. Moreover, the geographical location of Italy along the main migratory routes is a crucial factor to be considered for migratory birds, because they can be affected by blood parasites detected in feral pigeons, and vice versa.
\end{abstract}

Keywords: Feral pigeons, Columba livia, Haemoparasites, Haemoproteus spp., Leucocytozoon spp, Plasmodium spp

\section{Background}

Blood parasites have been subject of extensive research since the beginning of the 20th century [1]. The presence of haemoparasites in birds is very common, and it is estimated that $68 \%$ of all bird species are susceptible to haemosporidians [2,3]. Feral pigeons (Columba livia) are widely distributed in the world. Their number is increasing, especially in urban areas [4] . Haemoparasites in this species have been studied in several countries $[5,6]$, but to the authors' best knowledge no data on

\footnotetext{
* Correspondence: frineeleonora.scaglione@unito.it

'Dipartimento di Scienze Veterinarie, Università degli Studi di Torino, Via L. da Vinci 44, 10095 Grugliasco, Italy

Full list of author information is available at the end of the article
}

their presence in Italy are available. Therefore, the prevalence of Haemoproteus spp./Plasmodium spp. or Leucocytozoon spp. from pigeons culled by game wardens in the northwest of Italy has been determined. The possible associations between infection rate and different age or gender were also investigated. Moreover, considering that Italy is geographically situated on the main bird migratory routes, infection of feral pigeons with haemoparasites typical of other bird species could not be excluded, and vice versa.

\section{Methods}

During the years 2010-2011, following the adoption of a regional animal containment programme (according to 
the D.G.R no. 74-6702 [08/03/2007] and subsequent amendments), 51 feral pigeons (28 males and 23 females), from the Piedmont region (northwest Italy) were captured with Larsen cage traps. The animals were euthanized with $\mathrm{CO}_{2}$, according to Italian National Bioethics Committee guidelines, and to law no. 157 (02/11/1992) and subsequent amendments, and subjected to a standard necropsy procedure. Spleen was collected and frozen at $-20^{\circ} \mathrm{C}$ for biomolecular investigations. Age was determined by the colour of eyes and of the cere, according to the guidelines proposed by Beaman et al. [7].

Genomic DNA was extracted from sampled organs using a commercial DNA isolation kit (MACHEREYNAGEL, Düren, Germany), according to the manufacturer's protocol. The extracted templates were used for DNA amplification by mean of a thermal cycler (Gene Amp PCR System 2400, Perkin Elmer, Waltham, MA 02451, USA), using a specific primer set, as described by Scaglione et al. [8], exploiting the modified Hellgren et al. [9] protocol. A positive control DNA for each tested parasite was obtained from individuals with known infection obtained from eagles owl (Bubo bubo) tested by blood smears and PCR [10]. Each amplicon obtained from the second PCR step was visualized by means of agarose gel electrophoresis.

All positive samples were sequenced by Macrogen Europe (Amsterdam, the Netherlands), with the primers used for the second step of the nested PCR. Sequences were manually edited using BioEdit 7.0.5.3 and cytochrome $b$ gene haplotypes, defined by a sequence difference of at least one base in the amplified fragment, were identified using the Nucleotide BLAST application of GenBank [11]. Mixed infections were recognized by the presence of double peaks on the electropherograms [12]. Whenever possible, the identities of the parasites involved were assessed by comparing the double peak patterns with previously known sequences of parasite haplotypes infecting pigeons obtained from GenBank and MalAvi. New sequences were given a name according to MalAvi nomenclature [13] and deposited in GenBank.

Statistical analysis was performed using GraphPad Prism software (GraphPad Inc., San Diego, CA). The association between sex or age and infection status was evaluated using the chi-squared test for independence or Fisher's exact test. A p value less than 0.05 was considered statistically significant.

\section{Results}

Out of the 51 feral pigeons tested by nested PCR, 15 (29.4\%) resulted positive for Haemoproteus/Plasmodium spp. and 8 (15.7\%) for Leucocytozoon spp. A highly significant difference between the haemoparasites prevalence $(\mathrm{p}<0.001)$ was detected. There were no significant differences on infection status according to either bird age or sex.

The coinfection with both haemoparasites was very significant $(\mathrm{p}<0.01)$, and a greater relative risk $(R R, 7.2)$ to be infected by a second haemoparasite was recorded in already infected birds.

Regarding sex and age distribution of multiple infestation in pigeons associations were significant only in males $(\mathrm{p}<0.05$; $R R$ 11.0) and in adult birds $(\mathrm{p}<0.05$; RR 10.0).

DNA sequencing of the eight PCR positive samples for Leucocytozoon spp. allowed identifying six different lineages: five of them were the same identified in Hooded crows investigated by the authors in the same area (LC2; LC3, LC4; LC5; LC6: Scaglione et al., unpubl. data, [GenBank: KJ128987; KJ128989; KJ128990; KJ128991; KJ128988]), the other was a new lineage in feral pigeons (L-AEMO02). In two animals, two different lineages of Leucocytozoon (LC3-LC6 and LC2-LC4) were present at the same time. DNA sequencing of the 15 PCR positive samples for Haemoproteus/Plasmodium spp. showed the presence of the already described haplotypes P-SGS1 and H-HAECOL1. One Leucocytozoon sample and five Haemoproteus/Plasmodium samples that scored positive on the PCR analyses could not be sequenced, despite repeated amplification.

\section{Discussion}

Haemoparasites in birds have been object of many investigations $[1,14]$. Usually blood samples are taken from free-living birds during bird ringing, in order to evaluate morphology of haemoparasite in blood cells and grading parasitaemia with light microscopy, and to identify different lineages by PCR. Blood samples and blood smears were not collected in this project because animals were captured in accordance with current national regulations through Larsen cage traps and immediately euthanized. After a standard necropsy, the spleen of each animal was tested by PCR for haemoparasites. Spleen, being a well perfused and easily removable organ, with an important role in destruction of parasitized cells [15], can be used as a substitute of blood, useful to identify an erythrocytic or megalomeront stage. In fact, during these stages of development, the spleen should test positive by PCR. Furthermore, megalomeronts can be detected anywhere in the bird organism, but most of all in the spleen [1].

Several studies on birds haemoparasites [16-18] demonstrate that young animals are more prone to be infected by haemoparasites, even if the majority of authors indicated that adults have a greater prevalence of infection by various groups of haemosporidians [19]. Other authors showed that there were no differences in the prevalence of bird infections in different age groups [20], as reported in the present investigation. 
Numerous endogenous and exogenous factors may have a cumulative influence on the infection status of both sexes of the pigeons by these parasites, such as the host's hormones and humoral compounds, age and nutritional conditions, behaviour and habits, as well as the season of the year and ecological and physical features of the regions [6]. Usually, females are more parasitized because the reduction of the locomotion activity during the nesting period is a factor increasing the probability of their infection with haemosporidians [1].

In the present study, a significant association between sex and infection status was not detected. However, as the animals were captured from October to March, probably nesting related differences could not have been observed due to a reduced laying of eggs in this period. Moreover, in this species both male and female can hatch eggs.

Statistical differences in PCR detection of Haemoproteus/ Plasmodium spp. and Leucocytozoon spp. infection may be due to variation in vector diversity and population size, and avian community composition $[1,21,22]$.

The finding of avian haematozoa in pigeons implies the presence of ornithophilic vectors in Piedmont region and the susceptibility of this species to infection. Many bird hosts could be simultaneously infected by several species or strains of parasites [23-25]. According to the literature, Haemoproteus spp. is the most frequently observed blood parasite in birds, followed by Leucocytozoon spp. and Plasmodium spp. [26-28]. In Columbidae $[5,6,28,29]$, prevalence for each of them is strictly correlated to the geographical area. Sequences analysed in this study revealed respectively positivities of $56.3 \%, 43.8 \%$, and $6.3 \%$, for the three species. The coinfection with Haemoproteus spp., Plasmodium spp. and Leucocytozoon spp. in tested samples showed that the presence of a haemoparasite predisposes to other haemosporidian infections, in particular in males and in adult birds.

Coinfections with two or more different malaria parasites are common in wild birds [30] and it is possible to find several haemosporidia lineages both in a population and in the individuals [9]. Beadell et al. [31] found mixed infections in $29 / 428$ (6.8\%) individuals in their study on the prevalence of two avian blood parasite genera (Plasmodium and Haemoproteus) in the AustraloPapuan region. In a recent study in New Zealand, double infections with Plasmodium relictum and Plasmodium rouxi were found in blackbirds [32]. There are discrepancies in the literature about the effect of coinfections with different strains of Plasmodium, although these are generally considered more virulent than infections with just a single strain [33-35]. Heavy parasitaemia (over $35 \%$ and up to $90 \%$ during peaks) was found in three species of experimentally infected passerines, but the authors did not note any significant effect in body mass
[35]. In contrast, Marzal et al. [34] found a negative additive cost in body condition in individuals from a natural population of House Martins (Delichon urbicum) experimentally infected by two different Plasmodium strains [36].

The L-AEMO2 Leucocytozoon spp. lineage [GenBank: KJ152637] has been observed in Aegypius monachus in Spain (Pérez-Rodríguez et al., unpubl. data, [GenBank: HF543622]). The other lineages of Leucocytozoon spp. identified in feral pigeons have never been observed before in non-passerine birds. The L-CORNIX02 and LCORNIX06 lineages have been previously observed in Corvus corone and Corvus macrorhynchos in Japan (Yoshimura et al. unpubl. data [GenBank: AB741499, AB741505]) and in Corvus corone cornix in Italy in the same area. The LC3, LC4 and LC5 lineages have been previously identified only in Corvus corone cornix in Piedmont. Similar sequences with a homology of $99 \%$ (473/479 bp) have been registered in Pycnonotus jocosus in Switzerland (van Rooyen and Christe, unpubl. data [GenBank: JX867112]).

The H-HAECOL1 Haemoproteus/Plasmodium spp. lineage has been previously recorded in Columbida $[25,37]$ being repeatedly detected in pigeons and many other species of wild and domestic birds worldwide [38-42]. Reported infection rates were highly variable (range 18.8\%-76.5\%) but all the animals positive for Haemoproteus presented the H-HAECOL1 lineage 13, in contrast to Al-Barwari and Saeed [6], hypothesized that female pigeons are more prone than males to infection by H-HAECOL1. On the other hand, Senlik et al. [42] were unable to detect a significant difference in the infection rate of this parasite in terms of host sex, as already demonstrated in the present study.

Concurrent with the infection by H-HAECOL1, Dranzoa et al. [40] provided a figure of $29.4 \%$ for infection of the rock pigeons by Plasmodium parasites. In this study only one male pigeon was infected with $P$. relictum P-SGS1 lineage, not associated to other tested haemoparasites. The identified Plasmodium parasite has been observed worldwilde, mainly in passerine birds [43-45].

\section{Conclusion}

Blood parasites are related in many characters and considered by many authors to have either benign or mild effects $[39,18]$. They are continuously circulating around the world and any variation in their prevalence, intensity and health impact, whether sex-, seasonal- or spatialrelated, might depend on the susceptibility of the host species involved, their ages, habitats, as well as congruence, transmission, density and feeding habits of their vectors.

In the present paper the authors report novel host species for Leucocytozoon of corvids found in pigeons, and a 
novel Leucocytozoon species. Leucocytozoon parasites are not routinely found in pigeons. Moreover, the results hereby presented suggest that cross infection of feral pigeons with haemoparasites typical of other migratory or nonmigratory bird species is possible and should be further investigated and monitored. In fact, the geographical location of Italy along the main migratory routes is a crucial factor to be considered for migratory birds, because they can be affected by blood parasites transmitted by feral pigeons, and vice versa.

\section{Abbreviations \\ LC2: Leucocytozoon-CORNIX02; LC3: Leucocytozoon-CORNIX03; \\ LC4: LeucocytozoonCORNIX04; LC5: Leucocytozoon-CORNIX05; LC6: Leucocytozoon- CORNIX06; L-AEMO02: Leucocytozoon AEMO02; H-HAECOL1: Haemoproteus columbae 1; P-SGS1: Plasmodium relictum lineage SGS1.}

\section{Competing interests}

The authors declare that they have no competing interests.

\section{Authors' contributions}

FES carried out the necropsies, sampling, collection of data, molecular studies and helped to draft the manuscript; PP performed the statistical analysis and helped to draft the manuscript; FTC carried out the biomolecular studies, ADPR participated in the sequence alignment, EF participated in the design of the study and EB participated in the design and coordination of the study and helped to draft the manuscript. All authors read and approved the final manuscript.

\section{Acknowledgements}

The authors gratefully acknowledge the Centro di Referenza di Patologia Comparata "Bruno Maria Zaini", Italy; Prof. Javier Perez-Tris of the Department of Zoology and Physical Anthropology, Complutense University of Madrid, Spain and Spanish Ministry of Education for financial support (FPU studentship to APR).

\section{Author details}

${ }^{1}$ Dipartimento di Scienze Veterinarie, Università degli Studi di Torino, Via L. da Vinci 44, 10095 Grugliasco, Italy. ${ }^{2}$ Departamento de Zoología y Antropología Física, Universidad Complutense de Madrid, José Antonio Nováis 2, E-28040 Madrid, Spain.

\section{Received: 4 December 2014 Accepted: 20 February 2015}

Published online: 03 March 2015

\section{References}

1. Valkiūnas G. Avian malaria parasites and other haemosporidia. Boca Raton: CRC Press; 2005

2. Atkinson $C T$, Dusek RJ, Woods $\mathrm{KL}$, Iko WM. Pathogenicity of avian malaria in experimentally-infected Hawaii Amakihi. J Wildl Dis. 2000;36:197-204.

3. Valkiūnas $G$, Olsen $H$, lezhova T. Haemoparasites in the hooded crow, Corvus corone cornix L., in the vicinity of Copenhagen. Bull Scand Soc Parasitol. 2000;10:1-4

4. Dinetti M, Frassinet M. Ornitologia urbana. Bologna: Calderini Edagricole; 2001. p. 139-41.

5. Gupta DK, Jahan N, Gupta N. Distribution pattern of apicomplexan parasites (Sporozoa: Haemosporida) in Columba livia, Gmelin. J Parasit Dis. 2011:35:18-22.

6. Al-Barwari S, Saeed I. The parasitic communities of the rock pigeon Columba livia from Iraq: component and importance. Turkiye Parazitol Derg. 2012;36:232-9.

7. Beaman M, Madge S, Burn H, Zetterstrom D, Elliott M, Tucker L, Harris A, Hayman P: The handbook of bird identification: for Europe and the Western Palearctic - Christopher Helm, A \& C Black, London, Helm Identification Guides pp. 872. 1998

8. Scaglione FE, Cannizzo FT, Pregel P, Pérez-Rodríguez AD, Ferroglio E, Bollo E: Prevalence and distribution among organs of blood parasites in hooded crows (Corvus corone cornix) in Northwest Italy. Vet Ital, in press.
9. Hellgren $\mathrm{O}$, Waldenström J, Bensch S. A new PCR assay for simultaneous studies of Leucocytozoon, Plasmodium, and Haemoproteus from avian blood. J Parasitol. 2004;90:797-802.

10. Ortego J, Cordero PJ. PCR-based detection and genotyping of haematozoa (Protozoa) parasitizing eagle owls, Bubo bubo. Parasitol Res. 2009;104:467-70.

11. Genbank . [http://blast.ncbi.n/m.nih.gov/Blast.cgi].

12. Pérez-Tris J, Bensch S. Dispersal increases local transmission of avian malaria parasites. Ecol Lett. 2005;8:838-45.

13. Bensch S, Stjernman M, Hasselquist D, Ostman O, Hansson B, Westerdahl H, et al. Host specificity in avian blood parasites: a study of Plasmodium and Haemoproteus mitochondrial DNA amplified from birds. Proc Biol Sci. 2000:267:1583-9.

14. Lachish S, Knowles SC, Alves R, Wood MJ, Sheldon BC. Infection dynamics of endemic malaria in a wild bird population: parasite species-dependent drivers of spatial and temporal variation in transmission rates. J Anim Ecol. 2011;80:1207-16

15. John JL. The avian spleen: a neglected organ. Quarter Rev Biol. 1994;69:327-51.

16. Atkinson CT, Samuel MD. Avian malaria Plasmodium relictum in native Hawaiian forest birds: epizootiology and demographic impacts on apapane Himatione sanguinea. J Avian Biol. 2010;41:357-66.

17. Van Oers K, Richardson DS, Saether SA, Komdeur J. Reduced blood parasite prevalence with age in the Seychelles Warbler: selective mortality or suppression of infection? J Ornithol. 2010;151:69-77.

18. Sol D, Jovani R, Torres J. Geographical variation in blood parasites in feral pigeons: the role of vectors. Ecography Pattern Divers Ecol. 2000;23:307-14.

19. Knowles SC, Wood MJ, Alves R, Wilkin TA, Bensch S, Sheldon BC. Molecular epidemiology of malaria prevalence and parasitaemia in a wild bird population. Mol Ecol. 2011;20:1062-76.

20. Castro I, Howe L, Tompkins DM, Barraclough RK, Slaney D. Presence and seasonal prevalence of Plasmodium spp. in a rare endemic New Zealand passerine (tieke or saddleback, Philesturnus carunculatus). J Wild Dis. 2011;47:860-7.

21. Jenkins T, Owens IP. Biogeography of avian blood parasites (Leucocytozoon spp.) in two resident hosts across Europe: phylogeographic structuring or the abundance-occupancy relationship? Mol Ecol. 2011;20:3910-20.

22. Santiago-Alarcon D, Havelka P, Schaefer HM, Segelbacher G. Bloodmeal analysis reveals avian Plasmodium infections and broad host preferences of Culicoides (Diptera: Ceratopogonidae) vectors. PLoS One. 2012;7:e31098.

23. Bruce MC, Donnelly CA, Alpers MP, Galinski MR, Barnwell JW, Walliker D, et al. Cross-species interactions between malaria parasites in humans. Science. 2000;287:845-8.

24. Poulin R, Morand S. The diversity of parasites. Quarter Rev Biol. 2000;75:277-93.

25. Silva-Iturriza A, Ketmaier $V$, Tiedemann R. Prevalence of avian haemosporidian parasites and their host fidelity in the central Philippine islands. Parasitol Int. 2012;61:650-7.

26. Murata K. Prevalence of blood parasites in Japanese wild birds. J Vet Med Sci. 2002;64:785-90.

27. Savage AF, Robert V, Goodman SM, Raharimanga V, Raherilalao MJ, Andrianarimisa A, et al. Blood parasites in birds from Madagascar. J Wild Dis. 2009:45:907-20.

28. Carlson J, Martínez-Gómez JE, Valkiūnas G, Loiseau C, Bell DA, Sehgal RN Diversity and phylogenetic relationships of hemosporidian parasites in birds of Socorro Island, México and their role in the re-introduction of the Socorro Dove (Zenaida graysoni). J Parasitol. 2013;99:270-6.

29. Bunbury N, Barton E, Jones CG, Greenwood AG, Tyler KM, Bell DJ. Avian blood parasites in an endangered columbid: Leucocytozoon marchouxi in the Mauritian Pink Pigeon Columba mayeri. Parasitology. 2007;134:797-804.

30. Jarvi SI, Schultz JJ, Atkinson CT. PCR diagnostics underestimate the prevalence of avianmalaria (Plasmodium relictum) in experimentallyinfected passerines. J Parasitol. 2002:88:153-8.

31. Beadell JS, Covas R, Gebhard C, Ishtiaq F, Melo M, Schmidt BK, et al. Host associations and evolutionary relationships of avian blood parasites from West Africa. Int J Parasitol. 2009;39:257-66.

32. Gudex-Cross D. Avian malaria (Plasmodium spp.) in the Auckland region: host-parasite associations, capture technique bias, and landscape disease dynamics. Auckland, NZ: MSc thesis, Massey University; 2011.

33. Arriero E, Møller AP. Host ecology and life-history traits associated with blood parasite species richness in birds. J Evol Biol. 2008;21:1504-13.

34. Marzal A, Bensch S, Reviriego M, Balbontin J, de Lope F. Effects of malaria double infection in birds: one plus one is not two. J Evol Biol. 2008;21:979-87.

35. Palinauskas V, Valkiūnas $\mathrm{G}$, Bolshakov CV, Bensch S. Plasmodium relictum (lineage SGS1) and Plasmodium ashfordi (lineage GRW2): The effects of the 
co-infection on experimentally infected passerine birds. Exp Parasitol. 2011;127:527-33.

36. Schoener ER, Banda M, Howe L, Castro IC, Alley MR. Avian malaria in New Zealand. New Zealand Vet J. 2014;62:189-98.

37. Al-Janabi BM, Al-Sadi HI, Hayatee ZG. Some parasites of pigeons from Mosul province. J Coll Vet Med. 1980;1:15-26.

38. Martinez-Moreno FJ, Martinez-Mareno A, Becerra-Martell C, Martinez-Cruz M. Parasitic fauna of pigeons (Columba livia) in Cordoba Province, Spain. Rev Iber Parasitol. 1989;49:279-81.

39. Earle RA, Little RM. Haematozoa of feral rock doves and rock pigeons in mixed flocks. S Afr J Wildl Res. 1993;23:98-100.

40. Dranzoa C, Ocaido M, Katete P. The ecto-, gastro-intestinal and haemoparasites of live pigeons (Columba livia) in Kampala, Uganda. Avian Pathol. 1999;28:119-24.

41. Gulander A, Tuzer E, Cetinkaya H. Haemoproteus columbae infections and Pseudolynchia canariensis infestations in pigeons in Istanbul, Turkey. Istanbul Univ Vet Fak Derg Istanbul. 2002;28:227-9.

42. Senlik B, Gulegen E, Akyol V. Prevalence and intensity of Haemoproteus columbae in domestic pigeons. Indian Vet J. 2005;82:998-9.

43. Martinsen ES, Blumberg BJ, Eisen RJ, Schall JJ. Avian hemosporidian parasites from northern California oak woodland and chaparral habitats. J Wildl Dis. 2008;44:260-8.

44. Levin II, Zwiers P, Deem SL, Geest EA, Higashiguchi JM, lezhova TA, et al. Multiple lineages of avian malaria parasites (Plasmodium) in the Galapagos Islands and evidence for arrival via migratory birds. Conserv Biol. 2013;27:1366-77

45. van Rooyen J, Lalubin F, Glaizot O, Christe P. Avian haemosporidian persistence and co-infection in great tits at the individual level. Malar J. 2013;12:40.

\section{Submit your next manuscript to BioMed Central and take full advantage of:}

- Convenient online submission

- Thorough peer review

- No space constraints or color figure charges

- Immediate publication on acceptance

- Inclusion in PubMed, CAS, Scopus and Google Scholar

- Research which is freely available for redistribution 